\title{
Characterization and photocatalytic study of tantalum oxide nanoparticles prepared by the hydrolysis of tantalum oxo-ethoxide $\mathrm{Ta}_{8}\left(\mu_{3}-\mathrm{O}\right)_{2}(\mu-0)_{8}(\mu-\mathrm{OEt})_{6}(\mathrm{OEt})_{14}$
}

\author{
Subia Ambreen ${ }^{1}$, N D Pandey ${ }^{1}$, Peter Mayer ${ }^{2}$ and Ashutosh Pandey*1
}

\author{
Full Research Paper \\ Address: \\ ${ }^{1}$ Department of Chemistry, Motilal Nehru National Institute of \\ Technology, Allahabad, 211004, India and ${ }^{2}$ Department Chemie und \\ Biochemie, Universität München, Butenandtstraße 5-13, 81377 \\ München, Germany \\ Email: \\ Ashutosh Pandey* - apandey70@yahoo.com \\ * Corresponding author \\ Keywords: \\ bandgap; tantalum-oxo-ethoxide; Tauc plot; tantalum pentoxide \\ $\left(\mathrm{Ta}_{2} \mathrm{O}_{5}\right)$
}

Beilstein J. Nanotechnol. 2014, 5, 1082-1090. doi:10.3762/bjnano.5.121

Received: 07 January 2014

Accepted: 25 June 2014

Published: 18 July 2014

This article is part of the Thematic Series "Photocatalysis".

Guest Editor: R. Xu

(C) 2014 Ambreen et al; licensee Beilstein-Institut.

License and terms: see end of document.

\begin{abstract}
$\mathrm{Ta}_{8}\left(\mu_{3}-\mathrm{O}\right)_{2}(\mu-\mathrm{O})_{8}(\mu-\mathrm{OEt})_{6}(\mathrm{OEt})_{14}(\mathbf{1})$ was obtained by the controlled hydrolysis of tantalum ethoxide $\mathrm{Ta}(\mathrm{OEt})_{5}$ in the presence of ammonia. Compound $\mathbf{1}$ is considered as the intermediate building block in the sol-gel polymerization of Ta(OEt) 5 . Further hydrolysis of compound 1 yielded nanoparticles of $\mathrm{Ta}_{2} \mathrm{O}_{5}$, which were characterized by various techniques such as TGA-DTA-DSC, UV-vis DRS, XRD, SEM, TEM, particle size analyzer (DLS) and the Brunauer-Emmett-Teller (BET) method. The band gap of the particles was calculated by using the Tauc plot. The photocatalytic activity of $\mathrm{Ta}_{2} \mathrm{O}_{5}$ nanoparticles was tested by the degradation of the organic dye rhodamine $\mathrm{B}$.
\end{abstract}

\section{Introduction}

Metal alkoxides, being excellent precursors in the sol-gel process for preparation of metal oxides have attained huge attention of researchers. Several attempts have been made in order to modify the highly moisture sensitive metal alkoxides into less sensitive species [1-4] as precursors for metal oxides with new and better properties. However, due to the fast kinetics of the hydrolysis and condensation reactions in the sol-gel route, relatively little information is available concerning the progressive structural evolution in the transition metal oxide system in general. But sometimes new species, metal oxo-alkoxides [5-9], are obtained which have been known to be the direct molecular precursors for oxide phases in sol-gel technology. These oxo-species being treated as intermediates between the metal alkoxides and the metal oxides are very 
significant as they clearly indicate the route for the formation of oxides through hydrolysis. It is suggested that the hydrolysis of a metal alkoxide starts with the formation of a hydroxo derivative, which then forms the oxo derivative in a condensation step (Equation 1 and Equation 2).

$$
\begin{gathered}
\mathrm{M}(\mathrm{OR})_{x}+\mathrm{H}_{2} \mathrm{O} \rightarrow \mathrm{M}(\mathrm{OH})(\mathrm{OR})_{x-1}+\mathrm{ROH} \\
\mathrm{M}(\mathrm{OH})(\mathrm{OR})_{x-1}+\mathrm{M}(\mathrm{OR})_{x} \rightarrow \mathrm{M}_{2} \mathrm{O}(\mathrm{OR})_{2 x-2}+\mathrm{ROH}
\end{gathered}
$$

The investigation of the hydrolysis of titanium alkoxides showed that the reactions were very fast. Therefore the initial hydroxo compounds were not isolated [10]. Similar results were obtained for alkoxides of zirconium [11], tin(IV) [12], and uranium(V) [12]. Condensation can also occur even before hydrolysis via ether elimination between alkoxy groups leading to the formation of oxo bridges. The smaller size of $\mu$-oxo ligands coupled with the tendency of metal centers for coordination expansion, favors the condensation via ether elimination.

Oxo-alkoxides, being less reactive toward hydrolysis and condensation, are more stable than the corresponding alkoxides. They are generally observed for large and electropositive metals. Oxo-alkoxides are normally made of edge sharing $\mathrm{MO}_{6}$ octahedra. Usually the physical properties of metal oxo-alkoxides are decided by the degree of hydrolysis and the nature of the alkyl group. There is a tendency for lower volatility and solubility with higher degrees of hydrolysis and, therefore, oligomerization. Amongst the transition metal oxides, $\mathrm{Ta}_{2} \mathrm{O}_{5}$ has attracted growing interest due to its distinct properties such as large ion diffusion coefficient and high electrochromic reversibility, high dielectric constant, high refractive index, high chemical stability, large band gap [13-15] and photocatalytic activity for overall water decomposition and organic pollutant degradation [16-21].

The present work deals with the study of the controlled hydrolysis of tantalum ethoxide in the presence of ammonia and to prepare tantalum pentaoxide nanoparticles. In this process the stable intermediate tantalum oxo-ethoxide with composition $\mathrm{Ta}_{8}\left(\mu_{3}-\mathrm{O}\right)_{2}(\mu-\mathrm{O})_{8}(\mu-\mathrm{OEt})_{6}(\mathrm{OEt})_{14}(\mathbf{1})$ was isolated. When $\mathbf{1}$ was subjected to further hydrolysis it yielded nanoparticles of tantalum oxide after calcination at $750{ }^{\circ} \mathrm{C}$ for four hours. The photocatalytic activity of $\mathrm{Ta}_{2} \mathrm{O}_{5}$ nanoparticles was studied over the degradation of organic dye rhodamine $\mathrm{B}(\mathrm{RhB})$.

\section{Results and Discussion}

Tantalum penta-ethoxide was dissolved in toluene and with the aim to examine the effect of hydrolysis in basic medium, wet ammonia gas was purged into it with continuous stirring. After $1 \mathrm{~h}$ at $\mathrm{pH} 8.0$, a white solid was formed which was separated, re-dissolved in toluene and kept at low temperature for crystallization to give compound $\mathbf{1}$ as white shiny crystals in two days. The formation of tantalum oxo-alkoxide can be described as a result of following reactions (Equation 3 and Equation 4).

$$
\begin{aligned}
& 4 \mathrm{Ta}(\mathrm{OEt})_{5}+10 \mathrm{H}_{2} \mathrm{O} \rightarrow \mathrm{Ta}_{4}(\mathrm{OEt})_{10}(\mathrm{OH})_{10}+10 \mathrm{EtOH} \\
& 2 \mathrm{Ta}_{4}(\mathrm{OEt})_{10}(\mathrm{OH})_{10} \rightarrow \mathrm{Ta}_{8}(\mathrm{OEt})_{20} \mathrm{O}_{10}+10 \mathrm{H}_{2} \mathrm{O}
\end{aligned}
$$

${ }^{1} \mathrm{H}$ NMR of compound $\mathbf{1}$ shows many sets for ethoxy groups suggesting the presence of different types of ethoxy groups such as cis pairs of terminal OEt ligands, single terminal OEt ligands and $\mu$-OEt groups.

\section{Crystal structure}

Compound 1 was found in the monoclinic space group $P 21 / n$ with $Z=2$. The molecular structure (Figure 1) consists of a centrosymmetric unit of formula $\mathrm{Ta}_{8}\left(\mu_{3}-\mathrm{O}\right)_{2}(\mu-\mathrm{O})_{8}(\mu-$ OEt $)_{6}(\mathrm{OEt})_{14}(\mathbf{1})$. Each molecule has two $\mathrm{Ta}_{3}\left(\mu_{3}-\mathrm{O}\right)-(\mu-$ $\mathrm{OEt})_{3}(\mathrm{OEt})_{5}$ units linked with two $\mathrm{Ta}(\mu-\mathrm{O})_{4}(\mathrm{OEt})_{2}$ moieties by four $\mu$-oxo ligands. All of the tantalum atoms display distorted octahedral configurations. Six tantalum atoms are bonded to cis pairs of terminal ethoxy ligands and the other two are bonded to single ethoxy ligands. The terminal ligands are in trans position to the $\mu_{3}$ - and $\mu$-oxo atoms. The ethoxy groups are of two types. Out of the twenty ethoxy groups, fourteen are terminal while six $\left(\mathrm{O} 8, \mathrm{O} 9, \mathrm{O} 12\right.$ and $\left.\mathrm{O}^{*}, \mathrm{O} 9 *, \mathrm{O} 12 *\right)$ bridge the tantalum atoms. The tantalum atoms have two environments. Four tantalum atoms are coordinated to two terminal ethoxy, two bridging ethoxy, one $\mu-\mathrm{O}$ and one $\mu_{3}-\mathrm{O}$ ligands while two tantalum atoms

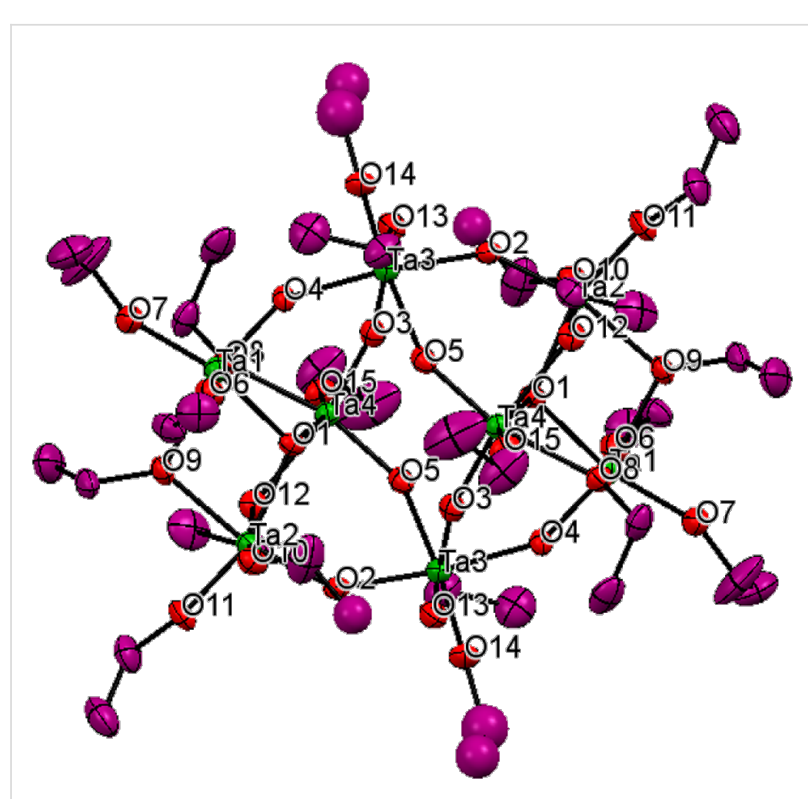

Figure 1: ORTEP representation of the molecular structure of 1 in the crystal (hydrogen atoms are omitted for clarity). 
are coordinated with two terminal ethoxy and four $\mu$-O groups. The $\mathrm{TaO}_{6}$ octahedra are distorted, resulting in $\mathrm{O}-\mathrm{Ta}-\mathrm{O}$ angles, which differ from those for a regular octahedron. Some bond lengths and bond angles are presented in Table 1 and Table 2 respectively. Ta-O bond lengths for the terminal ethoxy ligands are shorter (av. $1.897 \AA$ ) than the bridging ethoxy ligands (av. $2.153 \AA$ ). The $\mu$-oxo bridges are shorter than the $\mu_{3}$-O bond lengths (approx. $2.0585 \AA$ ). The $\mu_{3}$-oxo atom, O1 is ligated in pyramidal manner to three tantalum atoms with an average bond angle of $108.87^{\circ}$. The bond dimensional data are in accordance with previously reported values [5,9]. Full crystallographic details have been deposited to the Cambridge Crystallographic Data Centre. Copies of the data can be obtained free of charge on request from the CCDC, 12 Union Road, Cambridge CB2 1EZ, UK; fax: (+44) 1223-336-033; or e-mail: deposit@ccdc.cam.ac.uk or http://www.ccdc.cam.ac.uk/conts/ retrieving.html quoting the deposition number CCDC 951412 for 1 .

\begin{tabular}{|llll|}
\hline \multicolumn{2}{|l}{ Table 1: Selected bond lengths. } & & \\
bond & length & bond & length \\
\hline O1-Ta1 & $2.0629(1)$ & O7-Ta1 & 1.8711 \\
O1-Ta2 & $2.0345(1)$ & O8-Ta1 & $2.1061(1)$ \\
O1-Ta4 & $2.0719(1)$ & O8-Ta4 & $2.1556(1)$ \\
O2-Ta2 & 1.8577 & O9-Ta1 & $2.1533(1)$ \\
O2-Ta3 & 1.9928 & O9-Ta2 & $2.1319(1)$ \\
O3-Ta3 & $2.0039(1)$ & O10-Ta2 & 1.8928 \\
O3-Ta4 & $1.8544(1)$ & O11-Ta2 & 1.8669 \\
O4-Ta3 & $2.0167(1)$ & O12-Ta2 & $2.1149(1)$ \\
O4-Ta1 & 1.8411 & O12-Ta4 & $2.1725(1)$ \\
O5-Ta3 & $2.0238(1)$ & O13-Ta3 & 1.9083 \\
O5-Ta4 & 1.8455 & O14-Ta3 & $1.8783(1)$ \\
O6-Ta1 & $1.8927(1)$ & O15-Ta4 & 1.8671 \\
\hline
\end{tabular}

Upon further subjecting to hydrolysis ( $\mathrm{pH} 9.0$ ), compound 1 initially gave a homogeneous gel which was heated to $80{ }^{\circ} \mathrm{C}$ before annealing at $750{ }^{\circ} \mathrm{C}$ to obtain $\mathrm{Ta}_{2} \mathrm{O}_{5}$ nanoparticles. The morphology and composition of $\mathrm{Ta}_{2} \mathrm{O}_{5}$ nanoparticles are greatly influenced by the $\mathrm{pH}$ value [22]. The agglomeration of nanoparticles is enhanced at low $\mathrm{pH}$ due to the fast rate of hydrolysis and acidic surface of $\mathrm{Ta}_{2} \mathrm{O}_{5}$ while at the $\mathrm{pH}$ values above 10 , instead of $\mathrm{Ta}_{2} \mathrm{O}_{5}$, tantalate salts are formed [22].

\section{Particle size and distribution of $\mathrm{Ta}_{2} \mathrm{O}_{5}$ nanoparticles}

In order to study the size and distribution of the nanoparticles XRD, SEM, TEM and DLS measurements were carried out. Figure 2 shows the XRD patterns of calcined $\mathrm{Ta}_{2} \mathrm{O}_{5}$ nanoparticles. The peaks at $2 \theta$ values of $23.06,28.62,37.02,46.94$, $50.54,55.72,58.84,64.18$, and $71.30^{\circ}$ revealed the $\mathrm{Ta}_{2} \mathrm{O}_{5}$

\begin{tabular}{|c|c|c|c|}
\hline bond & angle & bond & angle \\
\hline Ta1-01-Ta2 & 110.85 & O9-Тa2-011 & 89.83 \\
\hline Тa1-01-Тa4 & 107.48 & O9-Ta2-O12 & 87.09 \\
\hline Ta2-O1-Ta4 & 108.28 & O10-Ta2-O11 & 100.04 \\
\hline Ta2-O2-Ta3 & 144.86 & O10-Ta2-O12 & 167.96 \\
\hline Тa3-O3-Ta4 & 145.34 & O11-Ta2-O12 & 91.4 \\
\hline Та3-O4-Тa1 & 144.33 & O2-Тa3-O3 & 90.31 \\
\hline Тa3-O5-Ta4 & 144.09 & O2-Тa3-O4 & 173.29 \\
\hline Ta1-O8-Ta4 & 102.94 & O2-Ta3-O5 & 85.31 \\
\hline Ta1-O9-Тa2 & 103.87 & O2-Тa3-O13 & 96.48 \\
\hline Ta2-O12-Ta4 & 101.83 & O2-Тa3-O14 & 89.15 \\
\hline O1-Ta1-O6 & 99.79 & O3-Тa3-O4 & 83.84 \\
\hline O1-Тa1-07 & 154.81 & O3-Тa3-O5 & 84.94 \\
\hline O1-Тa1-08 & 72.52 & O3-Та3-013 & 168.36 \\
\hline O1-Ta1-09 & 71.58 & O3-Тa3-O14 & 95.05 \\
\hline O1-Ta1-O4 & 92.52 & O4-Тa3-O5 & 90.89 \\
\hline O6-Ta1-O7 & 97.78 & O4-Тa3-O13 & 88.77 \\
\hline O6-Ta1-O8 & 170.71 & O4-Тa3-O14 & 94.62 \\
\hline O6-Ta1-O9 & 87.55 & O5-Тa3-013 & 86.2 \\
\hline O6-Ta1-O4 & 95.44 & O5-Тa3-O14 & 174.46 \\
\hline O7-Тa1-O8 & 88.03 & O13-Тa3-014 & 94.49 \\
\hline O7-Ta1-O9 & 91.35 & O3-Ta4-O15 & 101.71 \\
\hline O7-Ta1-O4 & 103.66 & O3-Ta4-O1 & 91.83 \\
\hline O8-Ta1-O9 & 85.07 & O3-Ta4-O5 & 101.59 \\
\hline O8-Ta1-O4 & 90.18 & O3-Ta4-O8 & 88.23 \\
\hline O9-Ta1-O4 & 164.11 & O3-Ta4-O12 & 161.79 \\
\hline O1-Ta2-O2 & 93.37 & O15-Ta4-O1 & 157.42 \\
\hline O1-Ta2-09 & 72.57 & O15-Ta4-O5 & 101.66 \\
\hline O1-Ta2-O10 & 94.28 & O15-Тa4-O8 & 90.91 \\
\hline O1-Ta2-011 & 157.16 & O15-Ta4-O12 & 91.7 \\
\hline O1-Ta2-012 & 73.68 & O1-Ta4-O5 & 93.07 \\
\hline O2-Ta2-O9 & 165.72 & O1-Ta4-08 & 71.34 \\
\hline O2-Ta2-O10 & 94.45 & O1-Ta4-O12 & 71.76 \\
\hline O2-Ta2-O11 & 103.07 & O5-Ta4-O8 & 161.98 \\
\hline O2-Ta2-O12 & 86.52 & O5-Ta4-O12 & 87.48 \\
\hline O9-Ta2-010 & 89.2 & O8-Ta4-012 & 79.2 \\
\hline
\end{tabular}

phase with an orthorhombic structure. The average crystallite size calculated from Scherrer formula was found to be $28 \mathrm{~nm}$.

To reveal the morphology SEM image of the calcined $\mathrm{Ta}_{2} \mathrm{O}_{5}$ nanoparticles is shown in Figure 3. Evidently, $\mathrm{Ta}_{2} \mathrm{O}_{5}$ nanoparticles are irregularly shaped, agglomerated and exhibit a moderately uniform size distribution. The size distribution of the $\mathrm{Ta}_{2} \mathrm{O}_{5}$ nanoparticles was studied by DLS (Figure 4) in chloroform dispersion. Trioctylphosphine oxide (TOPO) was used as the surfactant for dispersing the nanoparticles in chloroform. It was found that the nanoparticles are almost uniformly distributed. TOPO is reported to fragment bigger nanoparticles or agglomerates into smaller ones. TOPO molecules attach to the metal oxide particle surface in such a manner that their 


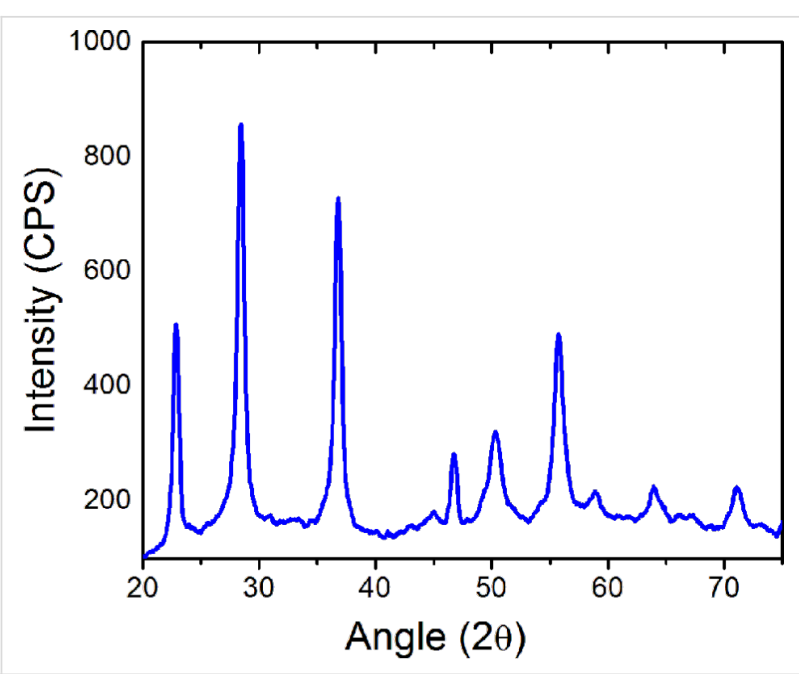

Figure 2: XRD pattern of $\mathrm{Ta}_{2} \mathrm{O}_{5}$ nanoparticles calcined at $750{ }^{\circ} \mathrm{C}$ for $4 \mathrm{~h}$.

hydrophobic surfaces point toward the solvent and render colloidal stability and uniformity of the particles in organic solvents [23]. The TOPO coated particles suspended in chloroform were precipitated by adding excess methanol followed by centrifuging at $2000 \mathrm{rpm}$ and re-dispersed in chloroform. A TEM image of the so obtained particles is shown in Figure 5.

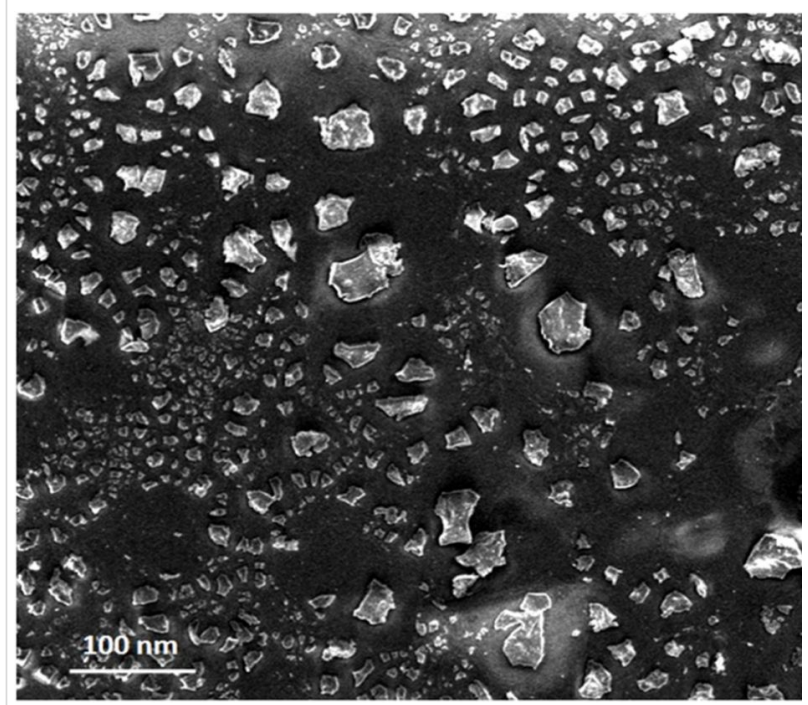

Figure 3: SEM image of $\mathrm{Ta}_{2} \mathrm{O}_{5}$ nanoparticles calcined at $750{ }^{\circ} \mathrm{C}$ for $4 \mathrm{~h}$.

\section{Thermal analysis of the prepared $\mathrm{Ta}_{2} \mathrm{O}_{5}$ nanoparticles}

Thermogravimetry, differential thermal analysis and differential scanning calorimetry (TG/DTA/DSC) with a heating rate of $10{ }^{\circ} \mathrm{C} / \mathrm{min}$ in a static air atmosphere were used to study the thermal stability of the as-prepared (dried) photocatalyst with

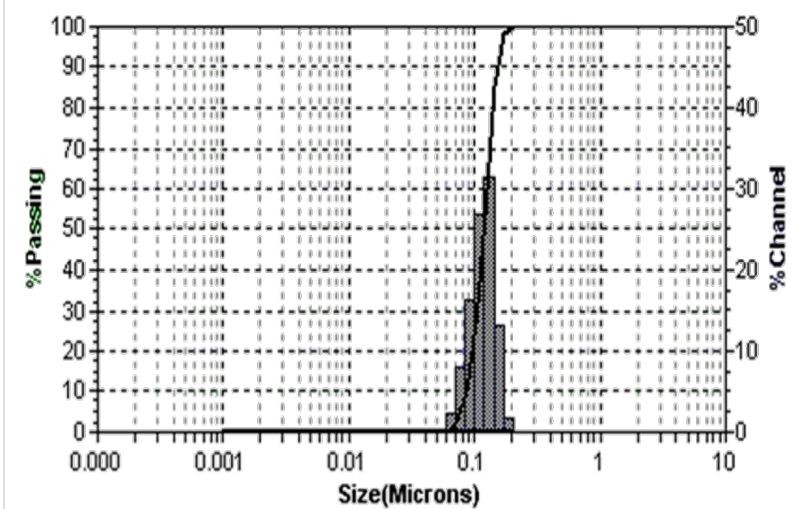

Figure 4: Size and distribution of TOPO-coated $\mathrm{Ta}_{2} \mathrm{O}_{5}$ nanoparticles in chloroform dispersion.

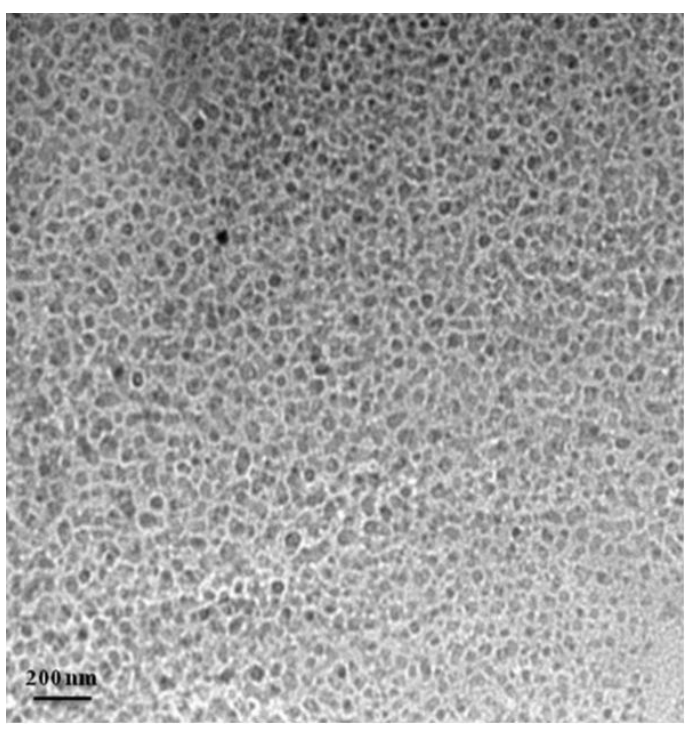

Figure 5: TEM image of the TOPO-coated $\mathrm{Ta}_{2} \mathrm{O}_{5}$ nanoparticles. The scale bar corresponds to $200 \mathrm{~nm}$.

$\alpha-\mathrm{Al}_{2} \mathrm{O}_{3}$ as the reference. Figure 6 shows the TG/DTA/DSC curves obtained from the dried gel of $\mathrm{Ta}_{2} \mathrm{O}_{5}$. The TGA graph shows a weight loss up to a temperature of $200{ }^{\circ} \mathrm{C}$ that is essentially attributed to dehydration. The decomposition of organic substances at $200-400{ }^{\circ} \mathrm{C}$ is caused by the decomposition of organic species inside the mesopores of the sample. Further the weight loss in the temperature range of $400-650{ }^{\circ} \mathrm{C}$ is due to a phase transition. An exothermic peak centered at $386.7^{\circ} \mathrm{C}$ in the DTA curve supports the statements above. The observation is also supported by the DSC graph.

\section{Band-gap determination of the $\mathrm{Ta}_{2} \mathrm{O}_{5}$ nanoparticles}

The band gap energy $\left(E_{\mathrm{g}}\right)$ is a key feature of semiconductors that determines their applications in optoelectronics. The 


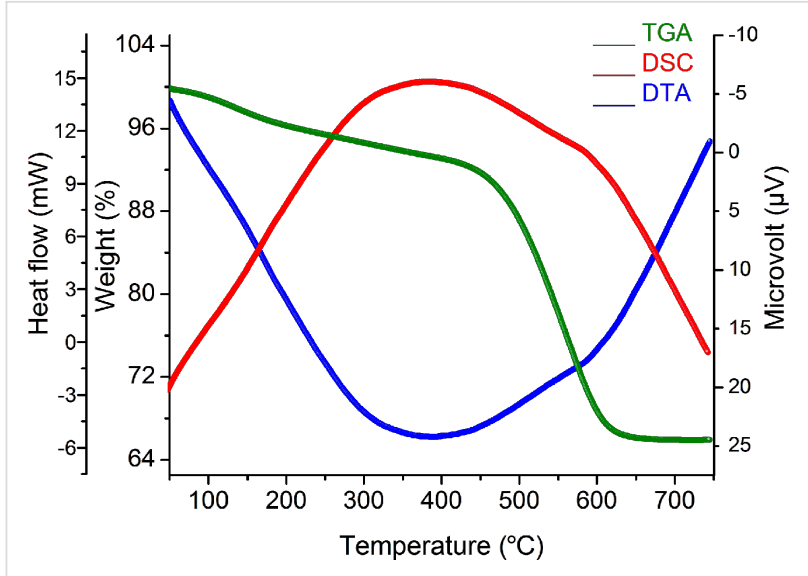

Figure 6: Thermogravimetry (TGA), differential thermal analysis (DTA) and differential scanning calorimetry (DSC) of the as-synthesized $\mathrm{Ta}_{2} \mathrm{O}_{5}$ nanoparticles.

nanoparticles were pressed into thick pellets and subject to diffuse reflectance measurement, which was done with a UV-vis spectrophotometer, attached with integrating sphere to spatially integrate the radiant flux. The pellets were placed at the entrance port of the integrating sphere. The absorption spectrum of $\mathrm{Ta}_{2} \mathrm{O}_{5}$ nanoparticles is shown in Figure 7. The reflectance data was converted to the absorption coefficient $F\left(R^{\prime}\right)$ values according to the Kubelka-Munk remission function [24-26] (Equation 5),

$$
F\left(R^{\prime}\right)=\left(1-R^{\prime}\right)^{2} / 2 R=\alpha / S
$$

where $\alpha$ is the absorption coefficient $\left(\mathrm{cm}^{-1}\right)$ and $S$ is the dispersion factor. The absorption coefficient $\alpha$ is related to the incident photon energy by Equation 6:

$$
\alpha=A\left(E-E_{\mathrm{g}}\right)^{n}
$$

$A$ is a constant for the given material, $E$ is the photon energy, $E_{\mathrm{g}}$ is the band gap energy and $n$ is a constant of different values, $1 / 2,3 / 2,2$ and 3 , depending on the type of electronic transition, i.e., permitted/prohibited-direct or indirect transition. The band gap is calculated from a Tauc plot [27-30]. The band gap of the $\mathrm{Ta}_{2} \mathrm{O}_{5}$ nanoparticles as calculated from the extrapolation of the linear portion of the plot in the $\alpha h v^{1 / 2}$ vs $h v$ graph to the abscissa (Figure 8) was found to be $3.9 \mathrm{eV}$.

\section{Brunauer-Emmett-Teller (BET) analysis}

The BET surface area of the calcined $\mathrm{Ta}_{2} \mathrm{O}_{5}$ nanoparticles was found to be $38.35 \mathrm{~m}^{2} / \mathrm{g}$. The total volume of pores with diameter less than $32 \AA$ at $P / P_{0}=0.400214547$ was estimated to be $0.022 \mathrm{~cm}^{3} / \mathrm{g}$ (Figure 9 and Figure 10).

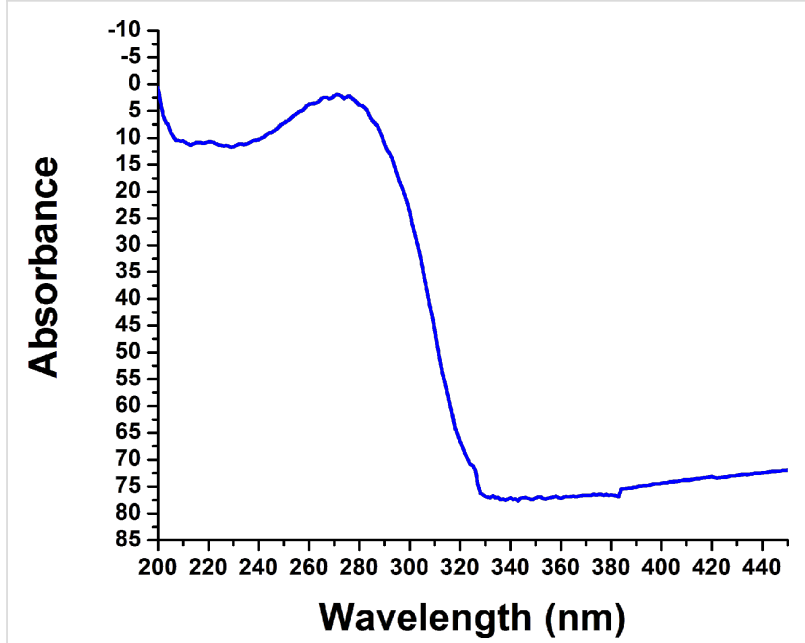

Figure 7: Solid state diffuse reflectance UV-vis spectra of $\mathrm{Ta}_{2} \mathrm{O}_{5}$ nanoparticles.

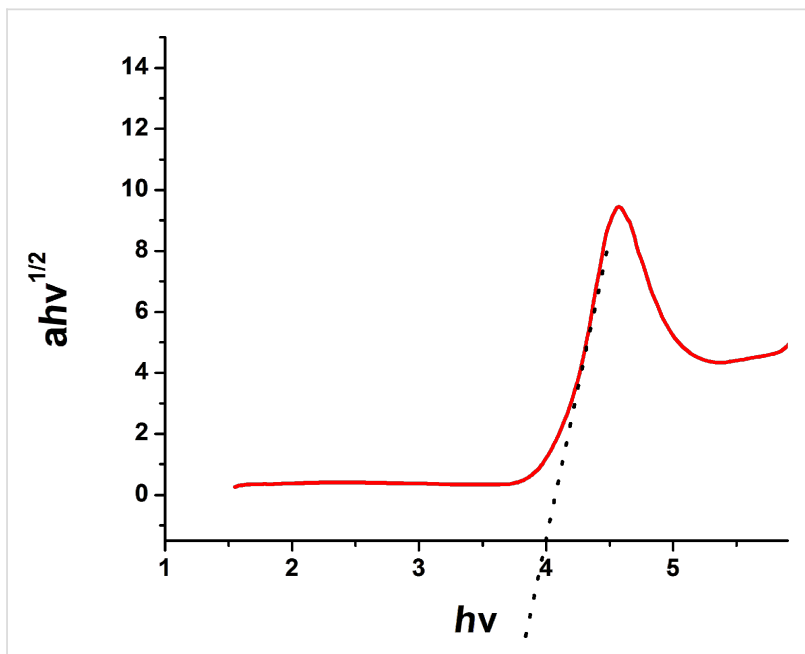

Figure 8: Calculation of band gap of $\mathrm{Ta}_{2} \mathrm{O}_{5}$ nanoparticles by Tauc plot.

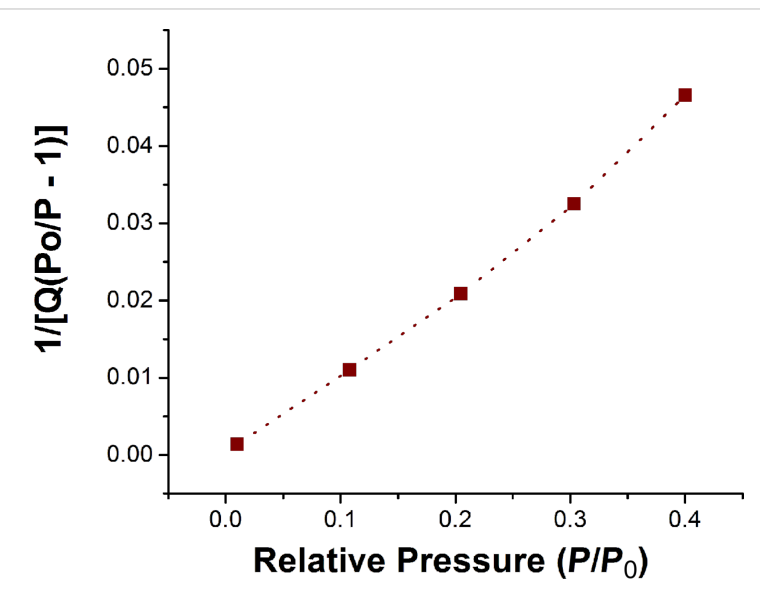

Figure 9: BET surface area plot of the calcined $\mathrm{Ta}_{2} \mathrm{O}_{5}$ nanoparticles. 


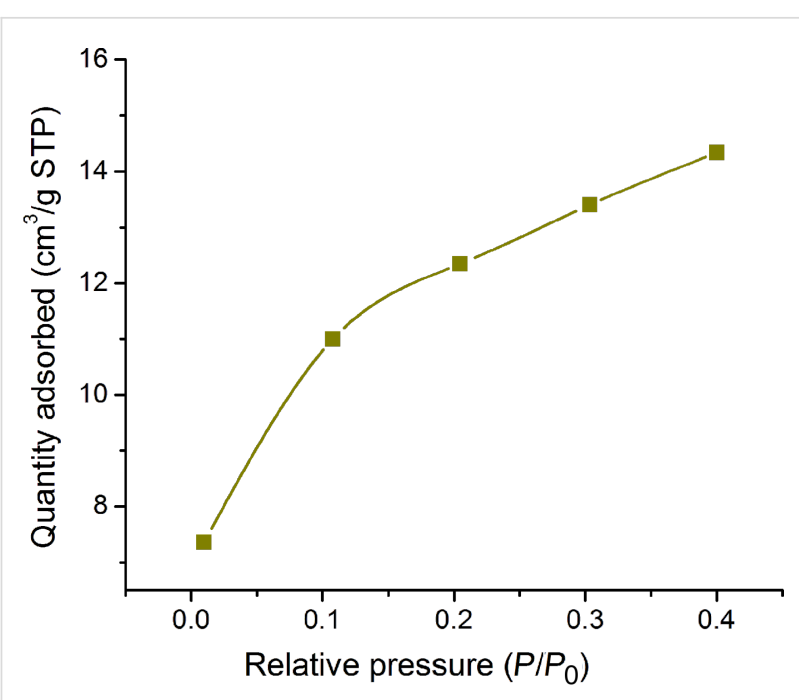

Figure 10: Degradation of rhodamine B by UV irradiation at $0.8 \mathrm{mg} / \mathrm{mL}$ catalyst loading.

\section{Photocatalytic experiments}

The photocatalytic activity was evaluated by the degradation of rhodamine $\mathrm{B}(\mathrm{RhB})$ under UV radiation for different amounts of $\mathrm{Ta}_{2} \mathrm{O}_{5}$. In each experiment $\mathrm{Ta}_{2} \mathrm{O}_{5}$ was added to $50 \mathrm{~mL}$ water and sonicated, followed by addition of RhB and exposure to UV light $(\lambda=365 \mathrm{~nm})$ irradiation at room temperature. To attain an adsorption-desorption equilibrium, the dispersion was stirred in the dark for $45 \mathrm{~min}$. Just before the irradiation an aliquot of $3.0 \mathrm{~mL}$ was taken and centrifuged. The supernatant was taken for recording the absorption spectrum at the initial concentration. After every $15 \mathrm{~min}$, an aliquot of $3.0 \mathrm{~mL}$ was taken and the concentration of $\mathrm{RhB}$ was measured through the intensity of absorption (Figure 11).

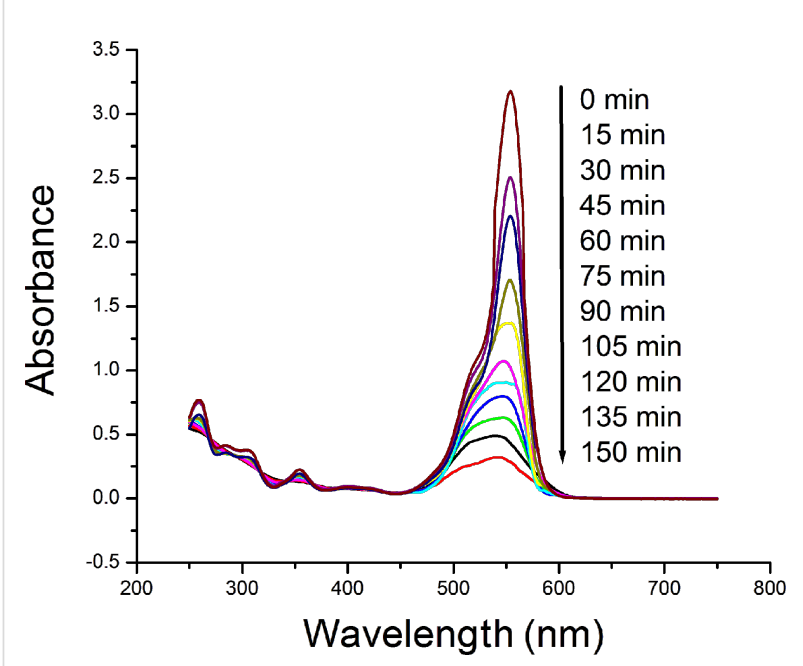

Figure 11: Effect of the concentration of $\mathrm{Ta}_{2} \mathrm{O}_{5}$ nanoparticles on the rate of degradation of rhodamine $B$.

\section{Effect of catalyst concentration on the rate of de- gradation of rhodamine $B$}

Figure 12 shows the degradation of dye for different of the catalyst loadings. It is clear that the optimum ( $89 \%)$ degradation of the dye was achieved (after 150 minutes) when $0.8 \mathrm{mg} / \mathrm{mL}$ of the photocatalyst was used in the experiment. However, when the used amounts of photocatalyst were $0.2 \mathrm{mg} / \mathrm{mL}, 0.5 \mathrm{mg} / \mathrm{mL}$ and $1.1 \mathrm{mg} / \mathrm{mL}$, the degradation of dye occurred up to $55 \%$, $68 \%$ and $74 \%$, respectively. The amount of the photocatalyst was changed in each experiment while keeping the other factors invariable to study the optimum degradation of dye with respect to the amount of $\mathrm{Ta}_{2} \mathrm{O}_{5}$. By increasing the amount of $\mathrm{Ta}_{2} \mathrm{O}_{5}$ from $0.2 \mathrm{mg} / \mathrm{mL}$ to $0.8 \mathrm{mg} / \mathrm{mL}$, the photocatalytic degradation rate was enhanced due to increase in the active sites accessible for the reaction on the surface of the catalyst. However, when the amount of catalyst was increased further, the rate of dye degradation was found to be lower. This may be due to the scattering of light from surface of the catalyst leading to the reduction in light penetration through the solution, which in turn reduces the rate of formation of radicals. Also, it may be assumed that the activated molecules get deactivated due to the collisions with the ground state molecules and thus reduce the degradation [31].

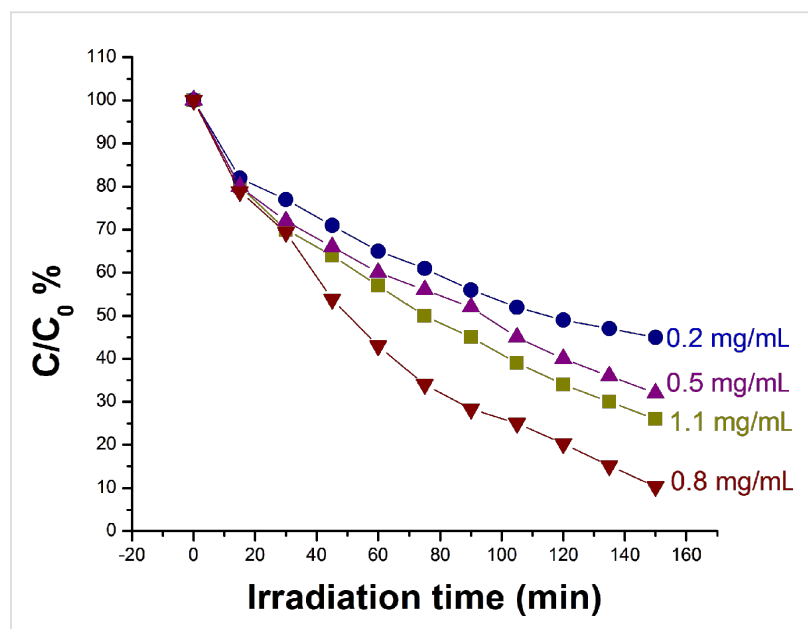

Figure 12: Effect of dye concentration on photocatalytic degradation.

\section{Effect of dye concentration on the rate of degrad- ation of rhodamine $B$}

To study the effect of initial dye concentration on the photocatalytic degradation different amounts of rhodamine B were taken while keeping other factors constant. It was observed that on increasing the amount of dye from $2.5 \mathrm{ppm}$ to $12.5 \mathrm{ppm}$ the rate of degradation of the dye increases but a further increase of the dye concentration decreases the degradation rate (Figure 13). With the increase in dye concentration the number of dye molecules available for excitation and intersystem crossing 
increases, which ultimately increases the rate of degradation. However, when the concentration of the dye was increased beyond a certain limit the excess of the dye serves as a filter for the light and also it does not allow the photons to reach the catalyst surface due to the reduced path length and, hence, retards the rate of degradation.

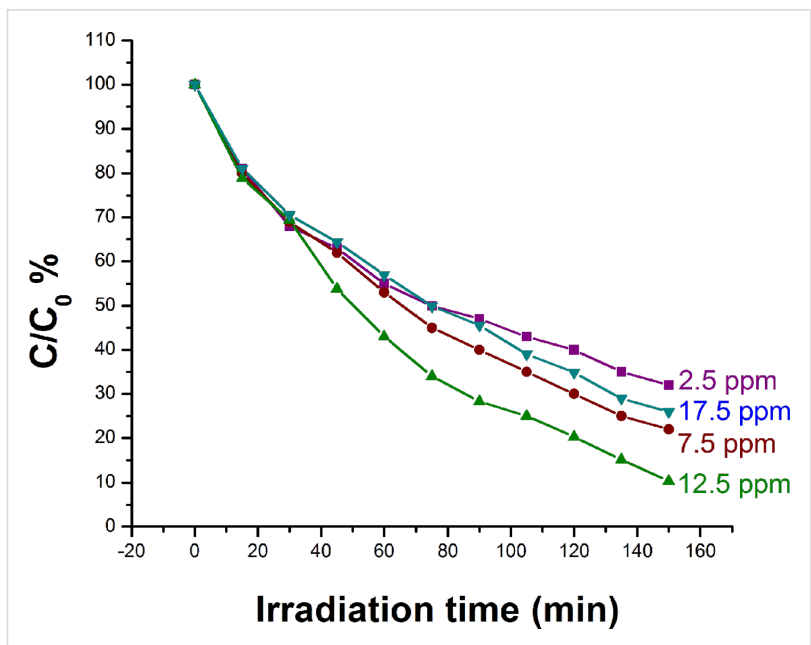

Figure 13: Effect of dye concentration on photocatalytic degradation.

\section{Effect of the $\mathrm{pH}$ value on the rate of degradation of rhodamine $B$}

Figure 14 shows the effect of the $\mathrm{pH}$ value on the rate of degradation of rhodamine $\mathrm{B}$. The $\mathrm{pH}$ value was adjusted by using dilute solutions of $\mathrm{HNO}_{3}$ and $\mathrm{NaOH}$. Degradation of the dye was studied at $\mathrm{pH} \mathrm{4,7}$ and 10. It was observed that the rate of degradation of rhodamine $\mathrm{B}$ increases with the increase in $\mathrm{pH}$ from 4 to 7. It appears that, when more hydroxy ions $\left(\mathrm{OH}^{-}\right)$are available, they combine with the holes $\left(\mathrm{h}^{+}\right)$of the semiconductor resulting in the production of hydroxyl radicals. These radicals are responsible for the degradation of dye by oxidative process. However, a further increase of the $\mathrm{pH}$ value provides excess $\mathrm{OH}^{-}$ions that get absorbed on the catalyst surface and obstruct the approach of the dye molecule to the catalyst surface and slow down the rate of degradation of rhodamine $B$ (Figure 14). Moreover, the metal oxide particles agglomerate at acidic $\mathrm{pH}$ and hence the surface available for dye absorbance as well as the photon absorption is reduced.

\section{Effect of calcination temperature}

As-synthesized $\mathrm{Ta}_{2} \mathrm{O}_{5}$ powder was calcined in at $650{ }^{\circ} \mathrm{C}$, $700{ }^{\circ} \mathrm{C}, 750{ }^{\circ} \mathrm{C}$, and $800{ }^{\circ} \mathrm{C}$. It was observed that $\mathrm{Ta}_{2} \mathrm{O}_{5}$ particles calcined at $750{ }^{\circ} \mathrm{C}$ possess best degradation efficiency (Figure 15). This may be due to increase in crystallinity and surface area with more active sites for photodegradation process when temperature is increased from $650^{\circ} \mathrm{C}$ to $750{ }^{\circ} \mathrm{C}$. A further increase in calcination temperature leads to bigger particles due

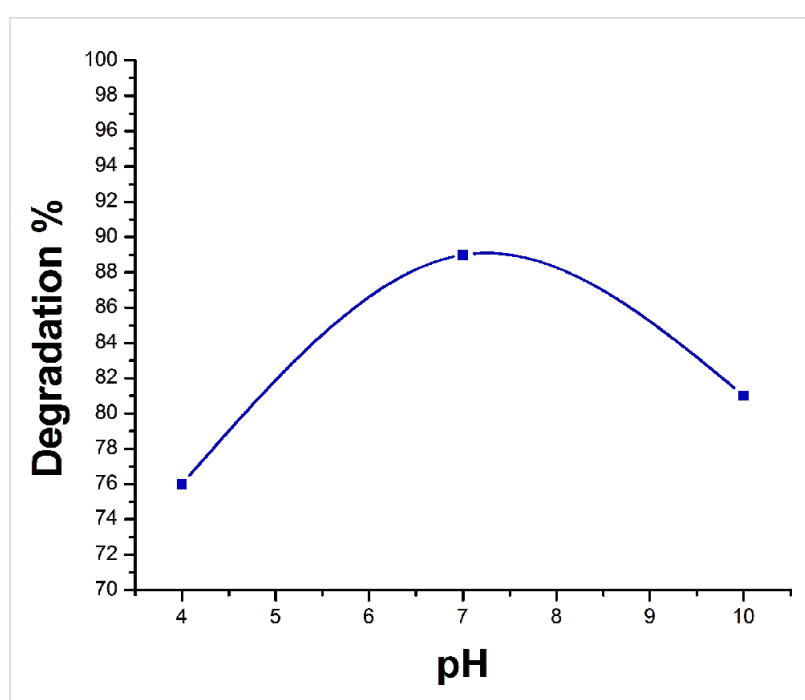

Figure 14: Effect of the $\mathrm{pH}$ value on the rate of degradation of rhodamine $\mathrm{B}$.

to agglomeration at higher temperature, which ultimately reduces the rate of degradation of rhodamine B [32]. At higher temperature the catalyst is deactivated due to sintering processes that result in a low surface area and smaller number of active sites [33].

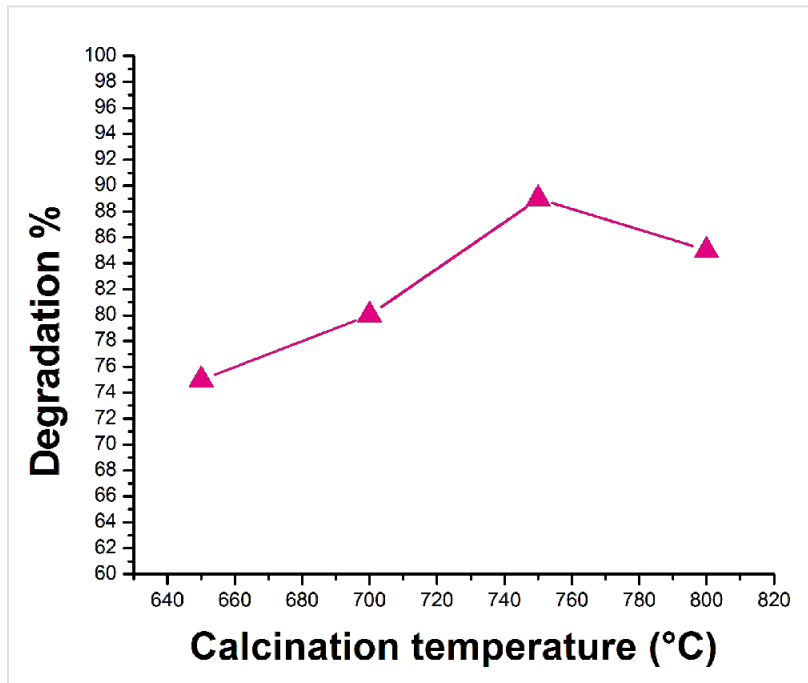

Figure 15: Effect of the calcination temperature on the rate of degradation of rhodamine $B$.

\section{Conclusion}

In summary, herein we report the formation of the tantalum oxo-ethoxide compound $\mathrm{Ta}_{8}\left(\mu_{3}-\mathrm{O}\right)_{2}(\mu-\mathrm{O})_{8}(\mu-\mathrm{OEt})_{6}(\mathrm{OEt})_{14}(\mathbf{1})$ through a sol-gel route in which hydrous ammonia gas was passed into a solution of tantalum ethoxide in toluene. $\mathrm{Ta}_{2} \mathrm{O}_{5}$ powder was obtained when a complete hydrolysis of 1 was allowed. After calcination the $\mathrm{Ta}_{2} \mathrm{O}_{5}$ nanoparticles were 
employed for the degradation of the common organic dye rhodamine B. The rate of degradation of the dye highly depends on the various parameters such as amount of the catalyst, dye concentration, $\mathrm{pH}$ and calcination temperature.

\section{Experimental}

All the reactions before the catalyst preparation were carried out under anhydrous conditions by using Schlenk/vacuum line techniques. Tantalum ethoxide was purchased from Sigma-Aldrich. Ethanol was dried by standard procedure prior to use. Ammonia gas was first dried by passing through the columns of silica gel, fused calcium chloride and aluminum isopropoxide, then it was passed into the distilled water through a tube with a diameter of $7 \mathrm{~mm} .{ }^{1} \mathrm{H}$ NMR spectra were recorded in $\mathrm{C}_{6} \mathrm{D}_{6}$ on a Bruker Biospin ARX spectrometer with TMS as internal reference. TGA/DTA/DSC was recorded by using a Diamond TG/DTAN instrument. X-ray diffraction patterns were recorded on SEIFERT XRD 3003 PTS Diffractometer System, using $\mathrm{Cu} \mathrm{K \alpha}$ radiation. SEM images was obtained on an EVO MA 15 Zeiss at $15 \mathrm{kV}$. DLS measurements were carried out on a Nanotrac particle analyser. The surface area was calculated by applying the Brunauer-Emmett-Teller (BET) method to $\mathrm{N}_{2}$ adsorption measurements on a Micromeritics ASAP 2020 instrument. TEM pictures were taken on a transmission electron microscope JEOL JEM-1011.

Preparation of 1: Tantalum ethoxide (100 mg) was dissolved in dry toluene $(20 \mathrm{~mL})$. Ammonia gas (passed through $20 \mathrm{~mL}$ distilled water at a rate of 30 bubbles/minute) was bubbled into the solution at ambient temperature. After $1 \mathrm{~h}$, a white solid precipitated. The solid was separated, re-dissolved in toluene and kept at $-30{ }^{\circ} \mathrm{C}$ for crystallization to yield compound 1 in $45 \%$ yield $(35 \mathrm{mg}) .{ }^{1} \mathrm{H}$ NMR $\left(25^{\circ} \mathrm{C}\right) \delta 1.33\left(\mathrm{t}, \mathrm{CH}_{3}\right), 1.41\left(\mathrm{t}, \mathrm{CH}_{3}\right)$, $1.49\left(\mathrm{t}, \mathrm{CH}_{3}\right), 1.58\left(\mathrm{t}, \mathrm{CH}_{3}\right), 1.62\left(\mathrm{t}, \mathrm{CH}_{3}\right), 4.45\left(\mathrm{q}, \mathrm{CH}_{2}\right), 4.59$ $\left(\mathrm{q}, \mathrm{CH}_{2}\right), 4.70\left(\mathrm{q}, \mathrm{CH}_{2}\right), 4.90-5.00,5.19\left(\mathrm{q}, \mathrm{CH}_{2}\right), 5.23$ (q, $\mathrm{CH}_{2}$ ).

Preparation of $\mathrm{Ta}_{2} \mathrm{O}_{5}$ nanoparticles: Compound $\mathbf{1}$ was dissolved in toluene and ammonia gas was blown into it for $6 \mathrm{~h}$ to get a homogeneous gel. After treating the gel at $80{ }^{\circ} \mathrm{C}$ for $3 \mathrm{~h}$, a white solid powder was separated out, which was insoluble in any organic solvent. The powder was washed with water and ethanol and dried at $100{ }^{\circ} \mathrm{C}$ for $2 \mathrm{~h}$. It was calcined at $750{ }^{\circ} \mathrm{C}$ for $4 \mathrm{~h}$ to develop crystallinity.

Photocatalytic activity measurements: Typical amounts $(0.2 \mathrm{mg} / \mathrm{mL}, 0.5 \mathrm{mg} / \mathrm{mL}, 0.8 \mathrm{mg} / \mathrm{mL}$ and $1.1 \mathrm{mg} / \mathrm{mL})$ of $\mathrm{Ta}_{2} \mathrm{O}_{5}$ nanoparticles as photocatalysts were taken in $50 \mathrm{~mL}$ of distilled water and sonicated for $5 \mathrm{~min}$. Then $12.5 \mathrm{ppm}$ of rhodamine B was added to it. To attain an adsorption-desorption equilibrium between the dye molecules and the catalyst surface, the solu- tion was stirred for about $45 \mathrm{~min}$ in dark prior to irradiation. Before exposing to the UV radiation $(\lambda=365 \mathrm{~nm})$, a $3 \mathrm{~mL}$ aliquot was taken, centrifuged and recorded as the zero time concentration of the dye. This process was repeated after every 15 min of exposure to UV light for recording the absorption of the remaining dye.

\section{Supporting Information}

\section{Supporting Information File 1}

CIF data of compound $\mathbf{1}$.

[http://www.beilstein-journals.org/bjnano/content/

supplementary/2190-4286-5-121-S1.res]

\section{Acknowledgements}

Subia Ambreen (SA) acknowledges University Grant Commission-Maulana Azad National Fellowship (UGC-MANF) for financial support. SA acknowledges useful discussions about the photocatalytic process with Mr. Shiv K. Pandey, MNNIT, Allahabad. Authors are grateful to Dr. Tamal Ghosh, Department of Chemistry, MNNIT, Allahabad, for providing UV-vis absorption facilities to perform the photocatalytic experiment. Authors also acknowledge the Department of Physics, MNNIT, Allahabad, for DRS and CIR-MNNIT, Allahabad, for the SEM facility.

\section{References}

1. Hubert-Pfalzgraf, L. G. Inorg. Chem. Commun. 2003, 6, 102-120. doi:10.1016/S1387-7003(02)00664-0

2. Pollard, K. D.; Puddephatt, R. J. Chem. Mater. 1999, 11, 1069-1074. doi:10.1021/cm981047a

3. Bradley, D. C. Chem. Rev. 1989, 89, 1317-1322. doi:10.1021/cr00096a004

4. Ambreen, S.; Gupta, K.; Singh, S.; Gupta, D. K.; Daniele, S.; Pandey, N. D.; Pandey, A. Transition Met. Chem. 2013, 38, 835-841. doi:10.1007/s11243-013-9756-y

5. Yanovsky, A. I.; Turova, N. Y.; Korolev, A. V.; Chebukov, D. E.; Pisarevsky, A. P.; Struchkova, Yu. T. Russ. Chem. Bull. 1996, 45, 115-121. doi:10.1007/BF01433743

6. Bradley, D. C.; Gaze, R.; Wardlaw, W. J. Chem. Soc. 1957, 469-478. doi:10.1039/jr9570000469

7. Day, V. W.; Eberspacher, T. A.; Klemperer, W. G.; Park, C. W.; Rosenberg, F. S. J. Am. Chem. Soc. 1991, 113, 8190-8192. doi:10.1021/ja00021a068

8. Schmid, R.; Mosset, A.; Galy, J. J. Chem. Soc., Dalton Trans. 1991, 1999-2005. doi:10.1039/DT9910001999

9. Abrahams, I.; Bradley, D. C.; Chudzynska, H.; Motevalli, M.; O'Shaughnessy, P. J. Chem. Soc., Dalton Trans. 2000, 2685-2691. doi:10.1039/B001797N

10. Bradley, D. C.; Gaze, R.; Wardlaw, W. J. Chem. Soc. 1955, 721-726. doi:10.1039/jr9550000721

11. Bradley, D. C.; Carter, D. G. Can. J. Chem. 1961, 39, 1434-1443. doi:10.1139/v61-183 
12. Bradley, D. C.; Holloway, H. Can. J. Chem. 1962, 40, 1176-1182. doi:10.1139/v62-179

13. Nashed, R.; Hassan, W. M. I.; Ismail, Y.; Allam, N. K. Phys. Chem. Chem. Phys. 2013, 15, 1352-1357. doi:10.1039/c2cp43492j

14. Ezhilvalavan, S.; Tseng, T. Y. J. Mater. Sci.: Mater. Electron. 1999, 10, 9-31. doi:10.1023/A:1008970922635

15. Sayama, K.; Arakawa, H. J. Photochem. Photobiol., A: Chem. 1994, 77, 243-247. doi:10.1016/1010-6030(94)80049-9

16. Zou, Z.; Ye, J.; Sayama, K.; Arakawa, H. Nature 2001, 414, 625-627. doi:10.1038/414625a

17. Takahara, Y.; Kondo, J. N.; Takata, T.; Lu, D.; Domen, K. Chem. Mater. 2001, 13, 1194-1199. doi:10.1021/cm000572i

18. Kominami, H.; Miyakawa, M.; Murakami, S.; Yasuda, T.; Kohno, M.; Onoue, S.; Kera, Y.; Ohtani, B. Phys. Chem. Chem. Phys. 2001, 3, 2697-2703. doi:10.1039/b101313k

19. Murase, T.; Irie, H.; Hashimoto, K. J. Phys. Chem. B 2004, 108, 15803-15807. doi:10.1021/jp047874i

20. Yang, X.; Xu, L.; Yu, X.; Li, W.; Li, K.; Huo, M.; Guo, Y. Colloids Surf., A 2008, 320, 61-67. doi:10.1016/j.colsurfa.2008.01.019

21. Sreethawong, T.; Ngamsinlapasathian, S.; Suzuki, Y.; Yoshikawa, S. J. Mol. Catal. A: Chem. 2005, 235, 1-11. doi:10.1016/j.molcata.2005.03.021

22. Gömpel, D.; Tahir, M. N.; Panthöfer, M.; Mugnaioli, E.; Brandscheid, R.; Kolb, U.; Tremel, W. J. Mater. Chem. A 2014, 2, 8033-8040. doi:10.1039/C4TA00183D

23. Pandey, A.; Roy, M. K.; Pandey, A.; Zanella, M.; Sperling, R. A.; Parak, W. J.; Samaddar, A. B.; Verma, H. C. IEEE Trans. NanoBiosci. 2009, 8, 43-50. doi:10.1109/TNB.2009.2017316

24. Malčić, V. D.; Mikočević, Z. B.; Itrić, K. Tech. Gaz. - Univ. Osijek 2011, 18, 117-124.

25. Yang, L.; Kruse, B.; Miklavcic, S. J. J. Opt. Soc. Am. A 2004, 21, 1942-1952. doi:10.1364/JOSAA.21.001942

26. Licht, S.; Khaselev, O.; Ramakrishnan, P. A.; Soga, T.; Umeno, M. J. Phys. Chem. B 1998, 102, 2546-2554. doi:10.1021/jp9800564

27. Tauc, J.; Grigorovici, R.; Vancu, A. Phys. Status Solidi 1966, 15, 627-637. doi:10.1002/pssb.19660150224

28. Sánchez-Vergara, M. E.; Alonso-Huitron, J. C.; Rodriquez-Gómez, A.; Reider-Burstin, J. N. Molecules 2012, 17, 10000-10013. doi:10.3390/molecules170910000

29. Murphy, A. B. Sol. Energy Mater. Sol. Cells 2007, 91, 1326-1337. doi:10.1016/j.solmat.2007.05.005

30. Yakuphanoglu, F.; llican, S.; Caglar, M.; Caglar, Y. J. Optoelectron. Adv. Mater. 2007, 9, 2180-2185.

31. Byrappa, K.; Subramani, A. K.; Ananda, S.; Rai, K. M. L.; Dinesh, R.; Yoshimura, M. Bull. Mater. Sci. 2006, 29, 433-438. doi:10.1007/BF02914073

32. Zhu, Y.; Yu, F.; Man, Y.; Tian, Q.; He, Y.; Wu, N. J. Solid State Chem. 2005, 178, 224-229. doi:10.1016/j.jssc.2004.11.015

33. Sehested, J. J. Catal. 2003, 217, 417-426. doi:10.1016/S0021-9517(03)00075-7

\section{License and Terms}

This is an Open Access article under the terms of the Creative Commons Attribution License

(http://creativecommons.org/licenses/by/2.0), which permits unrestricted use, distribution, and reproduction in any medium, provided the original work is properly cited.

The license is subject to the Beilstein Journal of Nanotechnology terms and conditions:

(http://www.beilstein-journals.org/bjnano)

The definitive version of this article is the electronic one which can be found at:

doi:10.3762/bjnano.5.121 